\title{
Há algo de novo nas psicoses: uma perspectiva Freudiano-Lacaniana
}

\author{
There is something new in the Psychosis: a Freudian-Lacanian perspective
}

Hay algo nuevo en la psicosis: una perspectiva freudiano-lacaniana

\author{
Francis Juliana Fontana ${ }^{1 *}$
}

\begin{abstract}
RESUMO
Objetivos: Revisar os estudos freudianos a respeito da psicose, nos quais o delírio psicótico é tomado como tentativa de cura, e o pensamento lacaniano, que repensou a clínica e o tratamento a esses quadros mediante a formação dos fenômenos de linguagem. Métodos: Foi realizada a análise teórica de textos freudianos e lacanianos, destacando-se a divergência entre os dois autores no que diz respeito à indicação da técnica psicanalítica a psicóticos. Resultados: O conceito de transferência marca o paradigma fundamental do processo. A impossibilidade de o psicótico estabelecer uma relação transferencial foi denunciada por Freud. Em Lacan, existem evidências que anunciam o fenômeno transferencial como sustentáculo da ação da fala. Considerações finais: É justamente pelo delírio ter fracassado na tentativa do psicótico em organizar seu mundo, que ele pode endereçar a sua fala a um psicanalista e demandar uma análise. Desse modo, mesmo que o processo não ocorra, a relação é efetiva. Nesse sentido, essa escuta poderá proporcionar ao psicótico a possibilidade de construir um novo lugar no mundo para além do enclausuramento psiquiátrico.
\end{abstract}

Palavras-chave: Psicanálise, Psicose, Terapia Combinada.

\begin{abstract}
Objectives: To review the Freudian studies about psychosis, in which psychotic delusion is taken as an attempt to cure, and the Lacanian thinking, who reviewed the clinic and the treatment of these subjects through the formation of language phenomena. Methods: The theoretical analysis of Freudian and Lacanian texts was carried out, highlighting the divergence between the two authors regarding the indication of the psychoanalytic technique to psychotics. Results: The concept of transfer marks the fundamental paradigm of the process. The impossibility of the psychotic establishing a transferential relationship was denounced by Freud. In Lacan, there is evidence that announces the transferential phenomenon as a support of the speech action. Final considerations: It is because delusion has failed in the attempt of the psychotic to organize his world, that he can address his speech to a psychoanalyst and demand an analysis. Thus, even if the process does not occur, the relationship is effective. In this sense, this listening can give the psychotic the possibility of building a new place in the world beyond the psychiatric closure.
\end{abstract}

Keywords: Psychoanalysis, Psychosis, Combined Therapy.

1 Doutoranda no Curso de Pós-Graduação em Filosofia da Pontifícia Universidade Católica do Paraná. Curitiba-Paraná. *E-mail: francisjuliana@hotmail.com 


\section{RESUMEN}

Objetivos: Revisar los estudios freudianos acerca de la psicosis, en los cuales el delirio psicótico es tomado como intento de curación, y el pensamiento lacaniano, que revisó la clínica y el tratamiento a esos cuadros mediante la formación de los fenómenos de lenguaje. Métodos: Se realizó el análisis teórico de textos freudianos y lacanianos, destacándose la divergencia entre los dos autores en lo que se refiere a la indicación de la técnica psicoanalítica a psicóticos. Resultados: El concepto de transferencia marca el paradigma fundamental del proceso. La imposibilidad de que el psicótico establezca una relación transferencial fue denunciada por Freud. En Lacan, existen evidencias que anuncian el fenómeno transferencial como sustentáculo de la acción del habla. Consideraciones finales: Es por el delirio haber fracasado en el intento del psicótico en organizar su mundo, que él puede dirigir su discurso a un psicoanalista y demandar un análisis. De este modo, aunque el proceso no ocurra, la relación es efectiva. En ese sentido, esa escucha podrá proporcionar al psicótico la posibilidad de construir un nuevo lugar en el mundo más allá del enclavamiento psiquiátrico.

Palabras clave: Psicoanálisis, Psicóticos, Terapia Combinada.

\section{INTRODUÇÃO}

O presente artigo pretende explorar conceitos freudianos e lacanianos para demonstrar como a psiquiatria, diferentemente da psicanálise, limita o fenômeno delirante; e circunscrever o método psicanalítico no âmbito do tratamento das psicoses.

A retomada dos pressupostos freudianos em relação à formação da teoria das psicoses contribuiu para um avanço inigualável nesse âmbito, pois Freud ultrapassou os limites de sua época ao inscrever o sujeito na ordem da loucura. A relevância do seu legado teórico, no que diz respeito às psicoses, incluiu decisivamente o seu estudo de 1911, intitulado "Observações psicanalíticas sobre um caso de paranoia relatado em autobiografia, 'O caso Schreber" (FONTANA FJ, 2015). Trata-se, como o próprio nome sugere, de um texto que interpreta os relatos feitos por Schreber DP (1995). Em sua autobiografia, Memórias de um Doente dos Nervos, o próprio adoentado conduziu a investigação de sua enfermidade.

Freud, a partir de então, seguiu o novelo do labirinto dos sintomas até encontrar três objetivos correlatos à psicose: (i) dar sentido a uma experiência de desmantelamento; (ii) descobrir o vínculo com o outro; e, por fim, (iii) restabelecer uma temporalidade (FONTANA FJ, 2015). Freud S (2010) compreendeu que, após a catástrofe psíquica, "a formação delirante é na realidade tentativa de cura".

A contribuição lacaniana ao tema das psicoses se deu a partir dos estudos que realizou de certos textos freudianos. Ressignificou a teoria edípica, introduzindo o conceito de o Nome-do-Pai (entre 1955 e1956) e distinguiu três registros: o real, o simbólico e o imaginário, tripartição conceitual construída por ele. Para Lacan J (1998) a teoria da psicose se sustenta na teorização da foraclusão (Verwerfung) do Nome-doPaino registro simbólico, após a queda do apoio do imaginário e do encontro invasivo e inominável que advém do real. Essas contribuições relativas ao tratamento na perspectiva clínica foram descritas na psicanálise lacaniana especialmente no "Seminário 3, As psicoses" (LACAN J, 2008a) e no livro "Escritos" (LACAN J, 1998). Foi realizada uma análise teórica de textos freudianos e lacanianos, destacando-se a divergência entre os dois autores no que diz respeito à indicação da técnica psicanalítica a psicóticos.

\section{RESULTADOS}

Em 1910, em "Perspectivas futuras da terapêutica psicanalítica", Freud vislumbrou a aposta no método psicanalítico pelo fenômeno da transferência. Esse método visava ascender às portas do inconsciente por meio da fala, isto é, fazer falar o que o sintoma não pode dizer: resultado do conflito psíquico e via de acesso ao insuportável (FONTANA FJ, 2015).

No princípio, a psicanálise era interpretativa, mas a "técnica passou por uma transformação" de modo que, ao contornar as resistências, a transferência foi localizada como mola mestra do trabalho (FREUD S, 1969a).

REAS/EJCH | Vol. 11 (11) | e1034 | DOI: https://doi.org/10.25248/reas.e1034.2019 Página 2 de 7 
Em 1912, no texto "A dinâmica da transferência", o conceito foi articulado à "cadeia libidinal de alguém que se acha parcialmente insatisfeito, uma catexia que se acha pronta por antecipação" e que, alhures, volta-se para a figura do médico. Atento à impossibilidade de o psicótico investir libidinalmente, Freud contraindicou o método a tais quadros. Todavia, mencionou que "a transferência não se acha presa a este protótipo" (FREUD S, 1969b).

Já em 1938, Freud S (1969c) apontou a necessidade de renunciar à "ideia de experimentar um plano de cura com os psicóticos - renunciar a ele talvez ou para sempre ou apenas talvez por enquanto", até o momento em que se construa ou que seja encontrado "outro plano que lhes adapte melhor" para seguir com a psicanálise para esses pacientes. O impasse freudiano parecia estar ligado, portanto, ao fenômeno da transferência.

Lacan iniciou seus estudos sobre as psicoses em 1932, com sua tese de doutorado intitulada " $D a$ psicose paranóica e suas relações com a personalidade" (LACAN J, 2011). Em 1955, no livro "Seminário 3, As psicoses", Lacan J (2008) retomou os estudos freudianos acerca das memórias de Schreber e questionou a linguagem e a escrita nas psicoses. Preocupado com a relação entre a linguagem e a loucura, almejava localizar novos dispositivos teóricos justificáveis e aplicáveis ao trabalho clínico com psicóticos. Lacan J (1998) reformulou a questão do tratamento da psicose em 1956, nos "Escritos", com o artigo "De uma questão preliminar a todo tratamento possível da psicose". Nele, articulou as contribuições relativas ao tratamento na perspectiva clínica, mais especificamente por meio da formulação da teoria da foraclusão do Nome-do-Pai e pela distinção que propôs dos três registros, a saber: o real, o simbólico e o imaginário.

A psicanálise lacaniana colocou o Édipo freudiano sob a regência do Nome-do-Pai. Definiu a castração como uma operação simbólica que a criança constrói sobre um objeto imaginário: ser ela própria o falo materno. A relação simbiótica mãe-filho, à medida que o bebê cresce, deve ser reconfigurada e rompida por um elemento terceiro. Este rompimento é efetuado a partir de um agente, o pai: "nada menos que um pai real, não forçosamente, em absoluto, o pai do sujeito, mas Um-pai". O encontro com o pai real ou o representante da figura paterna é o responsável por retirar a criança da fase especular, isto é, do mundo onde só existem ela e a mãe (LACAN J, 1998).

Essa definição lacaniana é estritamente freudiana. Quanto ao falo, Freud não o diferenciava do pênis real. Entretanto, Lacan procurou definir apuradamente esse conceito: em relação à "função imaginária do falo, [...] Freud a desvelou como pivô do processo simbólico que arremata, em ambos os sexos, o questionamento do sexo pelo complexo de castração" (LACAN J, 1998, grifo do autor).

A função paterna, portanto, instaura a separação, o interdito do incesto, marcando a diferença entre o mundo da mãe e o mundo da criança: trata-se da anulação do ser da mãe na criança. Essa operação que insere a criança no mundo da linguagem, instalando a lei, é justamente a operação inacessível ao psicótico (FONTANA FJ, 2015).

O sujeito pode se defender da entrada no mundo da linguagem pelo processo do recalque, que Freud chamou Verdrängung. Desse processo psíquico surgem as neuroses. A Verwerfung, traduzida por "rejeição", é o processo que envolve a estrutura da psicose. Desse modo, assumindo que a Verwerfung primordial é efeito da negação da castração, o resultado é a foraclusão do significante do Nome-do-Pai: "a Verwerfung será tida por nós, portanto, como foraclusão do significante" (LACAN J, 1998).

Na década de 1950, no texto "De uma questão preliminar a todo tratamento possível da psicose" Lacan J (1998) afirmou que o mecanismo fundante da psicose é uma operação que ocorre no nível da linguagem. A linguagem coloca o ser no mundo e é marcada pelo discurso do Outro. Como o psicótico não tem a inscrição do Nome-do-Pai no registro simbólico, fica entregue a esse gozo mortífero que vem do Outro.

Nesse mesmo artigo, Lacan J (1998) elaborou a teoria do desencadeamento da psicose confiável na foraclusão do Nome-do-Pai no registro simbólico, como a causa fundamental, mas não a única, envolvida no processo do surto psicótico. Desse modo, podem-se reconhecer, na teoria lacaniana dos anos 1950, três condições proeminentes para o desencadeamento da psicose: (i) condição estrutural, deflagrada pela 
foraclusão do Nome-do-Pai; (ii) a quebra da identificação imaginária; (iii) o encontro com Um-pai. Nas psicoses, a temática fálica da linguagem não é sustentada pela função paterna, o caráter dialético entre significante e significado não ocorre e a mensagem do Outro, do mundo exteriorizado dos significantes, atinge o sujeito de forma invertida.

O significante segue inevitavelmente deslizando em distintos significados, não articulado a outro significante, como metodicamente acontece na clínica das neuroses. Fora do sentido do significante do Nomedo-Pai, nas psicoses, o Outro assume estatuto especial, visceral, persecutório e invasivo. Desse modo, a metodologia a ser retomada, recai em como Lacan realizou a análise dos fenômenos de linguagem no psicótico para propor uma possível estabilização na metáfora delirante (FONTANA FJ, 2015).

A análise dos conceitos lacanianos, retomados da teoria freudiana, permite repensar se os dispositivos mencionados são aplicáveis na atualidade, ou se há a necessidade de se averiguar novos dispositivos teóricos e clínicos mais condizentes com a nossa época. Para a busca da resposta a tais questões, recorrese às reformulações lacanianas elaboradas pelo psicanalista francês a partir dos anos de 1970, a chamada última clínica lacaniana (MILLER JA, 2009).

Em 1975, no Seminário 23, Lacan J (2007) conferiu ao Sinthoma estatuto de dispositivo clínico no trabalho com as psicoses. Todavia, os estudos atualizados recaiam sobre a possibilidade da construção do Sinthoma, a partir do fenômeno da transferência. Haveria em cena um modo novo de conduzir a transferência nas psicoses?

Para além do enunciado de que o analista não deve recuar diante das psicoses, Lacan J (2008) advertia que não se convocasse o sujeito ao esgotamento pela via da palavra e da associação livre. Em "De uma questão preliminar a todo tratamento possível da psicose" (LACAN J, 1998), o psicanalista francês avançou nessa reflexão, com a nota de abertura retomando o propósito do manejo da transferência. Em relação a esse fenômeno transferencial na psicose, as construções teóricas são poucas, mas acalentadoras. No "Seminário 11 , Os quatro conceitos fundamentais da psicanálise", ele arguiria que a transferência "dirige o modo de tratar os pacientes. Inversamente, o modo de tratá-los comanda o conceito" (LACAN J, 1988).

O declínio do Nome-do-Pai, na atualidade, fez emergir uma clínica de sujeitos entregues aos modos de gozo. Seguindo a recomendação lacaniana, tem-se que o modo de tratar esses sujeitos pode conduzir à transferência e, assim, o conceito de transferência também passa por transformações e atualizações que viabilizam o tratamento.

\section{DISCUSSÃO}

O método aplicável e mensurado no tratamento psicanalítico das psicoses viabiliza a tentativa de ciframento do gozo que invade o sujeito pela via dos fenômenos elementares, ou seja, por meio do delírio e da alucinação. $O$ tratamento deverá conduzir aos confins da transposição de objeto a sujeito. $O$ trabalho na clínica das psicoses deverá permitir um encontro de dois vazios: o do analista e o do sujeito. Como nas psicoses o Nome-do-Pai é inoperante, o psicótico sujeito-objeto ficará a-sujeitado ao Outro. Assim, a perspectiva contorna a possibilidade de se dizer "não" ao gozo invasivo que advém do Outro.

A trama analítica é uma experiência que concerne ao corpo e à linguagem nas psicoses. Tais conceitos serão repensados a partir das reformulações teóricas em torno do gozo, cuja definição "é aquilo que não serve para nada", ao passo que o sujeito padece daquilo que "se reduz a ser apenas uma substância negativa", visto que ninguém o força a nada, "senão o superego" (LACAN J, 2007). Na clínica das neuroses, o superego mortifica o sujeito ao ponto de o gozo se vincular ao imperativo superegóico: "goze?'. Já nas psicoses observa-se algo análogo, mas inversamente distinto, pois o gozo invade o sujeito sem que seja possível barrar essa invasão, visto que a função fálica é inoperante: o superego se mostra tirânico, feroz e pleno de sentido, exigência do Outro (LACAN J, 2008).

É pela internalização da lei da castração que o sujeito toma conhecimento da possibilidade do excesso. Esse paradigma pode ser tomado a partir do mito do pai da horda primitiva, segundo o qual a morte do pai anuncia aos filhos que era o pai quem gozava de todas as mulheres. Assim, o sujeito abdica do gozo quando

REAS/EJCH | Vol. 11 (11) | e1034 | DOI: https://doi.org/10.25248/reas.e1034.2019 Página 4 de 7 
aceita que é o outro quem goza, e não ele. Desse modo, o sujeito se inscreve no mundo abdicando do seu gozo. É exatamente dessa impossibilidade de abdicação que o psicótico padece, consequentemente permanecendo cúmplice do imperativo de gozo, que goza nele ou goza dele; e o corpo sem bordas fica refém do gozo do Outro.

A possibilidade de tratamento, portanto, recai sobre a tentativa de fazer borda, de prender com ganchos 0 sujeito que se encontra escalando a vida e que, no surto, despenca no precipício do gozo. Na psicose, quando o corpo é atingido, cai como tentativa de evitar o sofrimento. Contudo, nesse desarranjo, o despedaçamento do corpo acontece, possibilitando a invasão de gozo. Para aplacar essa sensação de violenta ocupação, nada mais resta ao sujeito e, assim, surgem os fenômenos elementares (FONTANA FJ, 2015).

No percurso da pesquisa, surgiram impasses no cerne da questão da direção do tratamento na clínica das psicoses. Assim, metodologias envolvendo a teoria e certos modelos clínicos brotaram. No entanto, é fato que ainda faltam dispositivos clínicos claramente delimitados. O impasse que envolve a teoria psicanalítica das psicoses, ou seja, a impossibilidade de se forjar um dispositivo mensurável, está ligado à particularidade da clínica, do caso a caso da prática psicanalítica. Entretanto, pela via da orientação lacaniana na clínica das psicoses, o analista testemunha e participa do esforço que o sujeito faz para conseguir inscrever algo que designe seu gozo, evoluindo do vazio de significação à significação (FONTANA FJ, 2015).

Como na psicose o significante permanente segue no deslizamento enlouquecedor pela ausência do ponto de basta, o delírio aparece como tentativa de ciframento do gozo. Ao analista, cabe ocupar um lugar suportável na transferência delirante, de modo a constituir-se como o Outro ao psicótico e, assim, edificar dispositivos que possam conduzir ao gozo barrado. Afinal, o discurso como articulação significante "detém os meios de gozar, na medida em que implica o sujeito" (LACAN J, 2008).

Portanto, repensar o tratamento psicanalítico das psicoses implica delimitar a via transferencial, os fenômenos de linguagem e a contenção do gozo rumo à construção da estabilização. Com o advento da modernidade e o paradigma da cultura, e às voltas com o mais-de-gozar, a inscrição do gozo fálico fica precária e novos sintomas surgem. Têm-se nesse mote as psicoses brandas, as psicoses medicadas e as psicoses ordinárias, entre outras (CAMPOS T et al., 2008).

Na clínica contemporânea ao Seminário RSI, a clínica borromeana proporciona uma nota de abertura na direção do tratamento, com o nó borromeano (o qual remete ao brasão do escudo da família italiana Borromeu). Com a formalização dos três registros, afirmou Miller JA (2009), Lacan J se despediu da clínica estrutural, redefiniu a clínica psicanalítica e a superou a partir da noção do nó, pois referenciou o funcionamento do sujeito. Neste nó, o simbólico limita o imaginário, o imaginário limita o real, e o real limita o simbólico. Na psicanálise lacaniana, as falhas na constituição do nó indicam desestruturações psíquicas.

Lacan afirmou que o analista não deve recuar diante das psicoses. O artigo "De uma questão preliminar a todo tratamento possível da psicose" (LACAN J, 1998) se encerra com a observação de que não se deseja ultrapassar Freud. Contudo, chama a atenção o fato de que o autor enfatiza com precisão o percurso do clínico, apresentando o primeiro momento do tratamento. A primeira parte do título do artigo "De uma questão preliminar" demonstra que o que está em jogo é a fase inicial do tratamento, a saber: a transferência e a questão da paternidade. Na segunda parte do título "a todo tratamento possível da psicose", o psicanalista escamoteia a questão do tratamento para lançar a novidade de que todo tratamento possível remete à impossibilidade do todo, pois não existe um todo possível.

A lógica do funcionamento psicótico é inapreensível. Qualquer tentativa de elucidação da psicose é um excesso de razão. Desse modo, após o desencadeamento do surto, o trabalho analítico permite ao psicótico oferecer ao analista o seu delírio como tentativa de organizar o mundo, bem como barrar o gozo que o invade. Esse processo exige cautela, pelo difícil equilíbrio entre a localização do gozo no campo do Outro e a possibilidade de localizá-lo no próprio analista (QUINET A, 2011).

A construção da metáfora delirante mostra-se como um dispositivo aplicável no tratamento das psicoses. Tal construção faz suplência ao Nome-do-Pai foracluído do registro simbólico: a metáfora tem a função de ponto de basta no deslizamento do significado sobre o significante. Não obstante, o tratamento parece

REAS/EJCH | Vol. 11 (11) | e1034 | DOI: https://doi.org/10.25248/reas.e1034.2019 Página 5 de 7 
convergir também para a contenção do gozo, pois não só a ausência da condição fálica como também os encontros com aquele podem causar o desencadeamento do surto. A evolução da clínica fez surgir no campo da psiquiatria e no campo psicanalítico um fenômeno típico: uma clínica do sujeito entregue ao gozo.

Um horizonte de tratamento se abre ao se retomar aquilo que Lacan nomeou de Sinthoma. O Sinthoma, inscrito para além da clínica estrutural, possibilita a contenção de gozo, apresentando-se como dispositivo teórico e clínico amplamente aplicável na direção do tratamento das neuroses e das psicoses. A partir dessa clínica, contemporânea ao Seminário RSI, a recomendação lacaniana recai sobre a possibilidade de criar um dispositivo no tratamento que permita o enlace dos registros (MILLER JA, 2009). Lacan (2007) aferiu: "vocês têm a possibilidade de ligá-los. Com o quê? Com o sinthoma, o quarto [elemento]". O funcionamento e a ligação de tais registros, articulados e devidamente envolvidos, são aceitáveis pelo referido Sinthoma. Tratase de um quarto elemento, uma letra que confere um estatuto de marca, uma cifra útil para se insistir na concatenação dos três registros (FONTANA FJ, 2015).

Esse dispositivo abrange o que existe fora do significante, fazendo um laço social de modo a consentir que o sujeito encontre ou construa uma barragem ao gozo invasivo. A construção em torno da Teoria do Gozo vai ao encontro da clínica nodal, e esta última se move em direção à apresentação do estatuto de Sinthoma. No já mencionado Seminário RSI, os três registros se sustentam pela amarração: considerar o pai como função que enlaça os três registros permite a ligação e a formação do nó; assim, a amarração é função própria ao Nome-do-Pai (FONTANA FJ, 2015).

A mudança conceitual no ensino lacaniano, da primeira à última clínica, tem início nos anos 1950 (LEITE MPS, 2010), quando a metáfora paterna, em sua posição de exceção, garantia a ordem das coisas. Posteriormente, nos anos 1970, foi necessário que a função paterna se apoiasse no Sinthoma. A mudança conceitual norteou a possibilidade da amarração entre real, simbólico e imaginário, anteriormente garantida pelo símbolo universal da castração, ou seja, pelo Nome-do-Pai. Após as reformulações em torno do conceito de real, tal amarração passou a ser garantida pela invenção singular do Sinthoma (MILLER JA, 2009).

Após a catástrofe psíquica, o analista participa da construção de uma cifra inscrita no Sinthoma, viabilizando-a. A eficácia desse dispositivo se constrói na possibilidade de sua aplicabilidade não permanecer restrita à inscrição do operador do Nome-do-Pai. Todavia, tal construto somente será possível após um árduo trabalho analítico, em que o profissional se coloca na posição de secretário do alienado, isto é, oferece sua escuta para que o psicótico possa estabelecer um laço transferencial, mas não uma escuta qualquer: tratase aí de saber escutar o que o psicótico manifesta na sua relação com o significante foracluído no simbólico para que, assim, seja erigida uma contenção de gozo, uma escrita, "uma cifra inscrita no Sinthoma" (FONTANA FJ, 2015).

Em 1977, Miller JA (2012) retomou o estudo da problemática da transferência, no livro "As Psicoses Ordinárias". No texto "Lalíngua da transferência nas psicoses", Henry F (In: MILLER JA, 2012) fez referência ao paradigma da transferência nas psicoses ao indicar que o fenômeno deve abranger um movimento, um manejo na posição em que o analista ocupa, possibilitando a montagem da neotransferência. Nesta última, o vínculo transferencial não se configura pelo modelo erotomaníaco ou persecutório, mas pela novidade. 0 analista recolhe um significante particular da fala do sujeito, que permite fazer signo, cifra, marca: "uma vez desprovido do significado, o significante funciona sozinho".

Assim, na parceria com o analista, a transferência aparece como possibilidade de forjar o laço social, o recorte de significante e o seu manejo, o que possibilita a reconstrução da história da vida do sujeito. 0 significante como função de Um, que envelopa toda cadeia significante, faz apelo ao efeito de sentido de forma alusiva, sem finalidade de significação. Desse modo, o psicanalista insiste em "se fazer o destinatário dos signos ínfimos do real de lalíngua, sem se preocupar com o sentido. [...] ele pode ter uma chance de se tornar o parceiro do psicótico na lalíngua da transferência", permitindo um enganche em um laço social (HENRY F. In: MILLER JA, 2012). Essa modalidade permite que o analista ocupe a "posição de um parceiro", que pode ser chamado "de analista sutil" o qual, com delicadeza, permite um novo enlace transferencial no qual o psicótico produz sua saída (NITZCANER D, 2018).

REAS/EJCH | Vol. 11 (11) | e1034 | DOI: https://doi.org/10.25248/reas.e1034.2019 Página 6 de 7 


\section{CONSIDERAÇÕES FINAIS}

A possibilidade de tratamento proposto a partir da clínica borromeana permite repensar o conceito de transferência, desde sua aplicabilidade em Freud até o seu manejo em Lacan. Esse ponto de avanço alcançado pelo presente estudo aponta para uma neoposição (ou neotransferência) na posição do analista. Trata-se de acolher a construção que o psicótico realiza rumo à estabilização. No entanto, a dificuldade poderá recair sobre a sutileza de decifrar e diferenciar o que é da ordem do significante Um, e o que é da ordem do delírio propriamente dito, pois fala e delírio se confundem facilmente. A direção do tratamento na atualidade converge para a articulação do Sinthoma. Com efeito, resta ao profissional acolher e validar o sujeito na produção dessa ancoragem, validada no Sinthoma. Tal construção se mostra mais eficaz e mais sólida do que a estabilização pela metáfora delirante apresentada até o momento. Desse modo, somente pela construção da neotransferência é que o sujeito psicótico poderá construir o Sinthoma.

\section{REFERÊNCIAS}

1. CAMPOS S, GONÇALVES S, AMARAL T. Psicoses ordinárias. Mental, 2008; 11:73-87.

2. FREUD S. Observações psicanalíticas sobre um caso de paranoia relatado em autobiografia ("O caso Schreber"): artigos sobre técnica e outros textos (1911-1913). São Paulo: Companhia das Letras, 2010; $376 \mathrm{p}$.

3. FREUD S. (1910) Perspectivas futuras da terapêutica psicanalítica. In: FREUD S. Cinco lições de psicanálise, Leonardo da Vinci e outros trabalhos (pp. 125-136). Rio de Janeiro: Imago, 1969a; 284p. Edição Standard Brasileira das Obras Psicológicas Completas: 11.

4. FREUD S. (1912) A dinâmica da transferência. In: FREUD S. O Caso Schreber, Artigos sobre a Técnica e outros trabalhos (1911-1913) (pp. 129-143). Rio de Janeiro: Imago, 1969b; 406p. Edição Standard Brasileira das Obras Psicológicas Completas: 12.

5. FONTANA FJ. Psicoses da teoria à clínica: uma perceptiva Freudiano-Lacaniana. Curitiba: Juruá, 2015; $142 p$.

6. HENRY F. Lalíngua da transferência nas Psicoses. In: MILLER JA. A psicose ordinária: a conversação de Antibes (pp. 155-186). Belo Horizonte: Scriptum, 2012; 432p.

7. LACAN J. Abertura da seção clínica. Ornicar? 1977; 9:7-14.

8. LACAN J. De uma questão preliminar a todo tratamento possível da psicose. In: LACAN J. Escritos. Rio de Janeiro: Zahar, 1998; 590p.

9. LACAN J. Escritos. Rio de Janeiro: Zahar, 1998.

10. LACAN J. Da psicose paranoica em suas relações com a personalidade. Rio de Janeiro: Forense Universitária, 2011.

11. LACAN J. O Seminário, livro 3: As psicoses. Rio de Janeiro: Zahar, 2008a; 380p.

12. LACAN J. O Seminário, livro 8: A transferência. Rio de Janeiro: Zahar, 1992; 488p.

13. LACAN J. O Seminário, livro 11: Os quatro conceitos fundamentais da psicanálise. Rio de Janeiro: Zahar, 1988; 280p.

14. LACAN J. O Seminário, livro 23: O Sinthoma. Rio de Janeiro: Zahar, 2007; 256p.

15. LACAN J. O Seminário, livro 20: Mais, ainda. Rio de Janeiro: Zahar, 2007; 160p.

16. LACAN J. O Seminário RSI (Real, Simbólico e Imaginário) (1974). (Inédito no Brasil) In: MILLER, JA. Perspectivas do Seminário 23 de Lacan: O sinthoma. Rio de Janeiro: Zahar, 2009.

17. LEITE MPS. Psicanálise lacaniana: cinco lições para analistas kleinianos. São Paulo: lluminuras, 2010; 269p.

18. MILLER JA. Perspectivas do Seminário 23 de Lacan: O sinthoma. Rio de Janeiro: Zahar, 2009; 199p.

19. MILLER JA. A psicose ordinária: a conversação de Antibes. Belo Horizonte: Scriptum, 2012; 432p.

20. NITZCANER D. Transferência. In: FREITAS C. (Coord.). Scilicet: As psicoses ordinárias a as outras - sob transferência (p. 351-353). São Paulo: Escola Brasileira de Psicanálise, 2018; 353p.

21. QUINET A. Teoria e clínica da psicose. Rio de Janeiro: Florense Universitária, 2011; 105p.

22. SCHREBER DP. Memórias de um doente dos nervos. Rio de Janeiro: Paz e Terra, 1995; 316p. 